\title{
BIOACTIVE POTENTIAL OF STREPTOMYCES VARIABILIS - DV-35 ISOLATED FROM THOTTADA MARINE SEDIMENTS, KANNUR, KERALA
}

\author{
SREEJETHA MANDAL, DIVYA, VEENA SREEDHARAN, KOKATI VENKATA BHASKARA RAO*
}

Department of Biomedical Sciences, Molecular and Microbiology Research Laboratory, School of Bio Sciences and Technology, VIT University, Vellore, Tamil Nadu, India. Email: kokatibhaskar@yahoo.co.in

Received: 11 August 2016, Revised and Accepted: 16 August 2016

\section{ABSTRACT}

Objective: This study was aimed to evaluate the bioactive potential (antimicrobial and antioxidant) of marine actinobacteria isolated from Thottada marine sediment, Kannur, Kerala.

Methods: The study involved isolation of marine actinobacteria from Thottada marine sediments, followed by antimicrobial and antioxidant activity of the crude extract. Finally, identification of potential isolates.

Results: In this study, a total of 6 actinobacterial colonies were isolated, out of which only one isolate DV-35 showed maximum anti-microbial and anti-oxidant activity. The isolate DV-35 showed maximum inhibitory activity against Gram-negative bacterial pathogens Pseudomonas aeruginosa (18 $\mathrm{mm})$ followed by Salmonella typhi $(17 \mathrm{~mm})$ and Klebsiella sp. (13 mm) at a dose of $100 \mu \mathrm{g} / \mathrm{ml}$. In antifungal activity, extract showed maximum activity against Aspergillus niger (19 mm) followed Aspergillus flavus $(17 \mathrm{~mm})$ at a dose of $100 \mu \mathrm{g} / \mathrm{ml}$. Simultaneously the extract was evaluated for its antioxidant activity. The potential isolate DV-35 also showed moderately higher antioxidant activity in various screening assay, viz., 2,2-diphenyl-1picrylhydrazyl scavenging assay (80.12\%), metal chelating assay and reducing power assay (76\%) at a concentration of $100 \mu \mathrm{g} / \mathrm{ml}$. Potential isolate DV-35 was identified as Streptomyces variabilis DV-35 using molecular 16S rRNA sequencing.

Conclusion: The results obtained suggest that the extract is having bioactive metabolites that can be considered as a potential source for antimicrobial and anti-oxidant drug development.

Keywords: Marine actinomycetes, Anti-microbial activity, Anti-oxidant activity, Pseudomonas aeruginosa, Aspergillus niger, Streptomyces variabilis.

(C) 2016 The Authors. Published by Innovare Academic Sciences Pvt Ltd. This is an open access article under the CC BY license (http://creativecommons. org/licenses/by/4. 0/) DOI: http://dx.doi.org/10.22159/ajpcr.2016.v9s3.14643

\section{INTRODUCTION}

In recent years, many novel bioactive metabolites are produced from natural products [1]. Pathogens are becoming highly resistance to available drugs and have become more problematic to human health. To overcome the worldwide resistance to these pathogenic bacteria, the discovery of new and novel antimicrobial drug is a thirst area of research [2]. A major role that caused drug resistance in pathogenic microbes is the improper usage of antibiotics. By altering their genetic structure and metabolism pathogenic microbes gain resistance toward common available antibiotics [3,4]. On the other hand, there is a pressing need for the development of bio-antioxidant drugs in the current world. Similarly, antioxidant compounds have an ability to inhibit the free radicals; these free radicals play a major role in the oxidization of nucleic acids, proteins, lipids which trigger the degenerative disease. Highly reactive oxygen species and free radicals are present in the biological system. Antioxidants can prevent disease like cancer, coronary heart disease and also have a wide range of applications as dietary supplements [5-7]. Along with these antioxidants have various industrial uses, such as with gasoline, to stop the degradation of rubber and in cosmetics and also as food preservatives [8]. Hence, there is an urgent need for the development of new antimicrobial and antioxidant drugs.

The members of the group actinobacteria are widely distributed in marine and terrestrial ecosystems. They are non-motile, aerobic and Gram-positive bacteria with high $\mathrm{G}+\mathrm{C}(70-80 \%)$ content in their DNA. Marine actinomycetes posses' high commercial and pharmacological interest and they are well-known producers of many secondary metabolites [9]. Marine actinobacteria are an important source of marine environment possessing many important and interesting features. Many clinical and pharmaceutical important natural products are produced from marine actinobacteria [10].
Streptomyces, Micromonospora, and Nocardia are the three most common genera in the marine environment which acted as a potential source for new novel antibiotics. More than $70 \%$ of antibiotics or bioactive compounds that are available now are contribution of marine actinobacteria [11]. Among the commercially available and widely used antibiotics (erythromycin, chloramphenicol, tetracycline and gentamicin), most of them are isolated from Streptomyces sp. For the discovery of new antibiotics marine actinobacteria still hold the key position. Search of new antimicrobial and antioxidant drugs from actinomycetes has risen due to the prevalence of antibiotic resistance pathogen and pharmacological limitations, respectively. To cope up with this researchers have started looking for novel micro-organisms in unexplored and unwanted environment. Relatively thottada marine sediments have never been explored for microbial diversity and microbial metabolites. This is the first report on the microbial resource of Thottada marine sediments. Due to the different types of soil present in this area, geographical variation and uniqueness it is quite likely that there is vast distribution of secondary metabolites producing marine actinobacteria in this environment. This study was focused on isolation of those marine actinobacteria from Thottada sediments samples and to evaluate their antimicrobial and antioxidant activity with the eventual objective of discovering novel bioactive compounds.

\section{METHODS}

\section{Chemicals and media}

All chemicals used were of the highest purity and analytical grade. Starch Casein Agar (SCA), Actinomycetes Isolation Agar (AIA), International Streptomyces agar-2 (ISP-2), ISP-7, ISP-4, Mueller Hilton Agar, potato dextrose agar, potato dextrose broth, nutrient broth, soluble starch, glucose, yeast extract, $\mathrm{CaCo}_{3}, \mathrm{FeSO}_{4} .7 \mathrm{H}_{2} \mathrm{O}, \mathrm{CuSO}_{4} \cdot 5 \mathrm{H}_{2} \mathrm{O}$, $\mathrm{ZnSo}_{4} .7 \mathrm{H}_{2} \mathrm{O}, \mathrm{MnCl}_{2} \cdot 4 \mathrm{H}_{2} \mathrm{O}$, ferrozine, ascorbic acid and 2,2-diphenyl-1picrylhydrazyl (DPPH) were purchased from Hi Media Laboratories, 
Mumbai, India. Potassium ferricyanide, ferric chloride, trichloroacetic acid and solvents were obtained from Sisco Research Laboratories Pvt. Ltd., Mumbai, India.

\section{Sample collection}

Soil sample was collected from Thottada marine sediment $\left(11.8424^{\circ} \mathrm{N}\right.$ $75.4214^{\circ} \mathrm{E}$ ) Kannur, Kerala. The soil sample was collected at a depth of $10-20 \mathrm{~cm}$ from the top layer and then the samples were transferred into sterile bag and transported to the laboratory. The collected samples were stored at $4^{\circ} \mathrm{C}$ for further studies.

\section{Isolation of marine actinobacteria}

The actinobacteria were isolated by spread plate technique on starchcasein agar and AIA after serial dilution in 50\% sea water. All agar plates were supplemented with $100 \mu \mathrm{g} / \mathrm{ml}$ potassium dichromate and nalidixic acid to avoid fungal and bacterial contamination and incubated at room temperature form 7 to 30 days. Powdery and leathery colonies were isolated, purified and stored at $4^{\circ} \mathrm{C}$ until further use [12].

\section{Fermentation of isolated actinobacterial culture}

In $50 \mathrm{ml}$ of production media (soluble starch: $25 \mathrm{~g}$, glucose: $10 \mathrm{~g}$, yeast extract: $2 \mathrm{~g}, \mathrm{CaCO}_{3:} 3 \mathrm{~g}, 1 \mathrm{ml}$ of trace elements in $1000 \mathrm{ml}$ distilled water), all six isolates were separately inoculated in $100 \mathrm{ml}$ conical flask at room temperature for 1 week in a shaker (200-150 rpm). After incubation, the broths were centrifugation at 10,000 rpm for 10 minutes and the supernatant was collected to carry out the activities.

\section{Antimicrobial activity}

\section{Antibacterial activity of actinobacterial isolates}

Agar well diffusion method was used to determine the antibacterial activity of the crude extract. Using a sterile gel borer $6 \mathrm{~mm}$ diameter of the well was made on agar media. Inoculums of clinical pathogens $(0.1 \mathrm{ml})$ were spread on the plates, and $100 \mu \mathrm{l}$ of crude extract $(20 \mu \mathrm{g} / \mathrm{ml}$ to $100 \mu \mathrm{g} / \mathrm{ml}$ ) was loaded in different wells to evaluate their activity against clinical pathogens such as Staphylococcus aureus, Escherichia coli, Salmonella typhi, Pseudomonas aeruginosa, and Klebsiella sp. As a positive control chloramphenicol was used and dimethyl sulfoxide without actinobacterial extract was used as blank. Plates were incubated for $24 \mathrm{hrs}$ at $37^{\circ} \mathrm{C}$. After $24 \mathrm{hrs}$ of incubation, plates were checked for the zone of inhibition [2].

\section{Antifungal activity of actinobacterial isolates}

Actinobacterial Isolate DV-35 was inoculated in production media and incubated for 5 days at $28^{\circ} \mathrm{C}$. After incubation, the cultures were centrifuged at 10,000 rpm for 15 minutes and the supernatant was collected for extract production. Inoculums of fungal pathogens $(0.1 \mathrm{ml})$ were spread on the plates, and $100 \mu \mathrm{l}$ of crude extract $(20 \mu \mathrm{g} / \mathrm{ml}$ to $100 \mu \mathrm{g} / \mathrm{ml}$ ) was loaded in different wells to evaluate the antifungal activity against Aspergillus niger and Aspergillus flavus. Plates were incubated for $24 \mathrm{hrs}$ at $37^{\circ} \mathrm{C}$. After $24 \mathrm{hrs}$ of incubation, plates were checked for the zone of inhibition [12].

\section{ANTIOXIDANT ASSAY}

\section{DPPH assay}

Sample volumes of $1 \mathrm{ml}$ were pipetted out into separate test tubes. $2 \mathrm{ml}$ of DPPH was added to the test tubes and then mixed. Methanol ( $3 \mathrm{ml}$ ) was used as blank. A mixture of $1 \mathrm{ml}$ of methanol and $2 \mathrm{ml}$ of DPPH acted as the control. All the test tubes were then incubated at room temperature for 30 minutes in a dark room. The absorbance was then measured at $517 \mathrm{~nm}$ using the ultraviolet spectrophotometer [13]. The anti-oxidant activity (\%) was calculated using the formula:

Antioxidantactivity $=(\mathrm{C}-\mathrm{T} / \mathrm{C}) 100$

Where, $\mathrm{C}$ is absorbance of control and $\mathrm{T}$ is absorbance of test.

\section{Reducing power assay}

A sample volume of $1.0 \mathrm{ml}$ was dissolved in $1.0 \mathrm{ml}$ of phosphate buffer and was mixed well with $1.0 \mathrm{ml}$ of $1 \%$ potassium $\mathrm{Fe}\left[\mathrm{K}_{3} \mathrm{Fe}(\mathrm{CN})_{6}\right]$, and then this mixture was incubated at $50^{\circ} \mathrm{C}$ for 20 minutes. Subsequently, $1.0 \mathrm{ml}$ of trichloroacetic acid and $1.0 \mathrm{ml}$ milliQ water were added. Finally, the solution was mixed with $0.1 \mathrm{ml}$ of $0.1 \%$ ferric chloride. The mixture was incubated at $50^{\circ} \mathrm{C}$ for 10 minutes. Absorbance was measured at $700 \mathrm{~nm}[14]$.

\section{Metal chelating assay}

The metal chelating activity of the extract was done by mixing $0.5 \mathrm{ml}$ of extract with $1.6 \mathrm{ml}$ milliQ water. Subsequently, $\mathrm{FeCl}_{2}(0.05 \mathrm{ml})$ of was added in a test tube. This reaction was initiated by the addition of $5 \mathrm{~mm}$ ferrozine $(0.1 \mathrm{ml})$. The solution was mixed well and allowed to stand for 10 minutes at $40^{\circ} \mathrm{C}$. After the incubation period, absorbance was measured using a spectrophotometer at $562 \mathrm{~nm}$. Distilled water was used as a control. Instead of $\mathrm{FeCl}_{2}$ distilled water was used as blank [15].

\section{Identification of potential marine actinobacterial strains}

Identification of the potential isolates showing good antimicrobial and antioxidant activity was done using the key of Nonomura [16] and methods of Shirling and Gottlieb [17]. Along with this species level identification was also confirmed using cell wall composition analysis and by micromorphological studies [18]. Finally, the complete identification was done using molecular characterization based on 16S rRNA sequencing (Yaazh Xenomics, Chennai, Tamil Nadu, India). Bacterial genomic DNA was isolated using the InstaGeneTM Matrix Genomic DNA isolation Kit. The fragments were amplified bidirectionally using the forward ( $5^{\prime}$-AGAGTTTGATCMTGGCTCAG- $\left.3^{\prime}\right)$ and reverse (5'- TACGGYTACCTTGTTACGACTT $-3^{\prime}$ ) primers (MJ Research Peltier Thermal Cycler). The sequence was analyzed by ABI 3730xl capillary DNA sequencer (ABI Prism 310 Genetic Analyzer, Tokyo, Japan). Finally, the sequence was observed for similarity using NCBI BLAST similarity tool.

\section{Statistical analysis}

Using two-way analysis of variance values were analyzed between groups of same or different dpi. All values are shown as mean \pm standard deviation. The significance of the differences between the mean values was determined using students $t$-test. For all statistical analysis $* \mathrm{p}<0.05$ were considered significant.

\section{RESULTS}

\section{Isolation of marine actinobacteria}

Isolation of marine actinobacteria was done on SCA and AIA. The result obtained in the present study reveals that the salt pan sediment samples are rich in actinobacterial population. From the collected samples, a total of 6 actinobacterial colonies were isolated. Considering the total number of isolates, the maximum number were isolated on AIA (4), followed by SCA (2). The isolates were identified by using culture characteristics as mentioned in ISP manual. All 6 isolates were belonging to the genera Streptomyces sp.

\section{Antibacterial activity of actinobacterial extract}

The bioactive potential of all 6 isolates was evaluated by testing their antibacterial potential against gram positive and negative bacteria. Among 6 only one isolate DV-35 showed antimicrobial activity against all test pathogens. Cell-free supernatant of DV-35 showed maximum inhibition against $P$. aeruginosa with a zone of inhibition of $18 \mathrm{~mm}$, followed by $S$. typhi $(17 \mathrm{~mm})$ and Klebsiella sp. (13 mm). Antibacterial profile shown by isolate DV-35 is represented in Table 1 . The extract showed maximum activity at a dose of $100 \mu \mathrm{g} / \mathrm{ml}$ against all test pathogens.

\section{Antifungal activity of actinobacterial extract}

Isolate DV-35 showed good antifungal activity against $A$. niger and A. flavus. Cell-free supernatant of DV-35 showed maximum zone of inhibition (19 mm) against $A$. niger at a dose of $100 \mu \mathrm{g} / \mathrm{ml}$ followed by $15 \mathrm{~mm}$ of inhibition at a dose of $80 \mu \mathrm{g} / \mathrm{ml}$. Similarly, DV-35 showed maximum activity against $A$. flavus $(17 \mathrm{~mm})$ at a dose of $100 \mu \mathrm{g} / \mathrm{ml}$ followed by $80 \mu \mathrm{g} / \mathrm{ml}$ with a zone of inhibition of $14 \mathrm{~mm}$ (Fig. 1). 
DPPH scavenging assay

DPPH assay is the reduction of purple color of DPPH in the presence of hydrogen-donating antioxidant, lead to the development of yellowcolored non-radical form of DPPH. The DPPH scavenging activity was increased with an increase in the cell-free extract. Maximum activity was observed at a concentration of $100 \mu \mathrm{g} / \mathrm{ml}$ (Fig. 2a). Isolate DV-35 showed $80.12 \%$ of DPPH scavenging activity with an inhibitory concentration $\left(\mathrm{IC}_{50}\right)$ value of $60 \mu \mathrm{g} / \mathrm{ml}$. The results indicate that the less dose of marine actinobacterial extract exhibited the capability to lessen the DPPH radical, which indicated that extract possesses excellent antioxidant activity.

\section{Reducing power assay}

Reducing power assay is measured by the electron donating capability of an antioxidant. $\mathrm{Fe}^{+}$complex gets converted to the ferrous form in

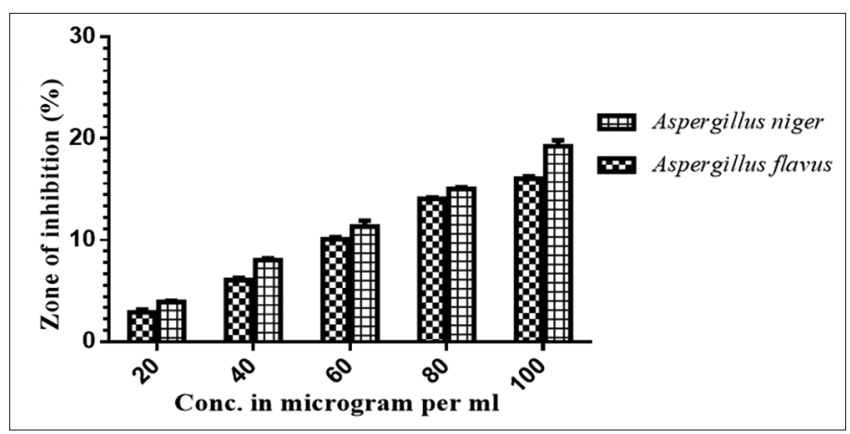

Fig. 1: Antifungal activity of isolate DV-35 against Aspergillus niger and Aspergillus flavus the presence of reducers, which is a significant indicator of antioxidant activity. The positive test was indicated by formation of green color. An increase in the absorbance of the reaction mixtures indicates an increase in reducing power. Potent isolate DV-35 showed maximum reducing power activity (Fig. $2 \mathrm{~b}$ ).

\section{Metal chelating assay}

Formation of ferrous and ferrozine complex interfered the antioxidant from marine actinobacteria, which suggests that actinobacterial crude extract poses metal chelating activity and captures ferrous ion before it reacts with ferrozine. Isolate DV-35 showed a good metal chelating assay with an $\mathrm{IC}_{50}$ value of $80 \mu \mathrm{g} / \mathrm{ml}$. At a dose of $100 \mu \mathrm{g} / \mathrm{ml} \mathrm{DV-35}$ showed maximum metal chelating activity (Fig. 2c).

\section{Identification of potential isolate DV-35}

Using 16S rRNA sequencing the potential isolate was identified as Streptomyces variabilis. Primary identification of potential strains done using the key of Nonomura, micromorphological studies and cell wall composition analysis also showed similar results (Table 2). Isolate DV-35 formed an extensively branched substrate mycelium which carried a rectiflexcible and smooth surface (Figs 3 and 4). Potential isolate showed $97 \%$ of similarity with $S$. variabilis in the blast search analysis. The $16 \mathrm{~S}$ rRNA sequencing of potential strains was confirmed that it occupies a distinctive phylogenetic position with the radiation, including representatives of the family using neighbor joining tree (Fig. 5).

\section{DISCUSSION}

Marine actinobacterial are known producers or secondary metabolites. In this world, there is a pressing need for the development of

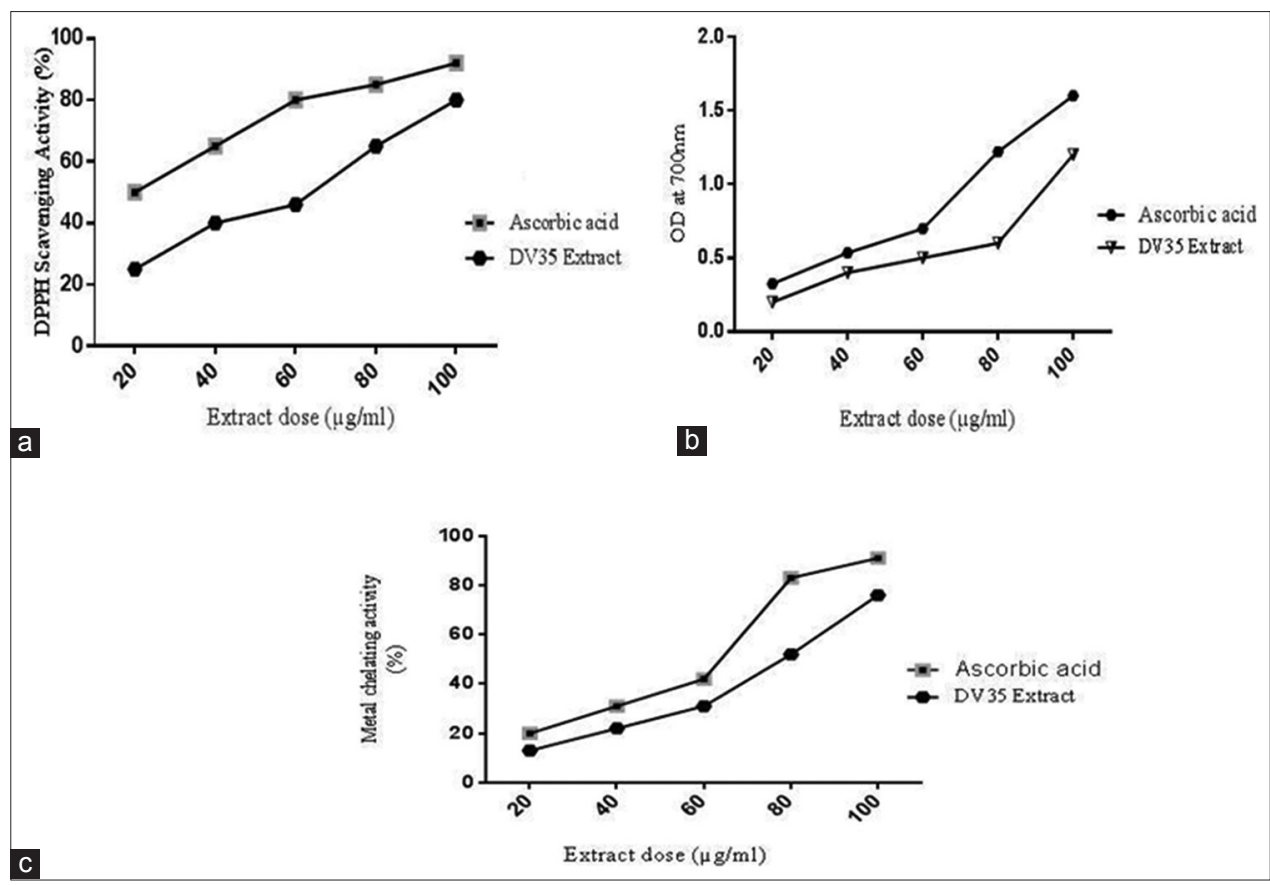

Fig. 2: Antioxidant activity (a) 2,2-diphenyl-1-picrylhydrazyl scavenging assay (b) Reducing power assay (c) Metal chelating activity

Table 1: Antibacterial activity of isolate DV-35

\begin{tabular}{|c|c|c|c|c|c|c|}
\hline \multirow[t]{2}{*}{ S.N } & \multirow[t]{2}{*}{ Pathogenic cultures } & \multicolumn{5}{|c|}{ Zone of inhibition } \\
\hline & & $20 \mu \mathrm{g} / \mathrm{ml}$ & $40 \mu \mathrm{g} / \mathrm{ml}$ & $60 \mu \mathrm{g} / \mathrm{ml}$ & $80 \mu \mathrm{g} / \mathrm{ml}$ & $100 \mu \mathrm{g} / \mathrm{ml}$ \\
\hline 1. & Staphylococcus aureus & $3 \mathrm{~mm}$ & $5 \mathrm{~mm}$ & $8 \mathrm{~mm}$ & $10 \mathrm{~mm}$ & $12 \mathrm{~mm}$ \\
\hline 3. & Salmonella typhii & $2 \mathrm{~mm}$ & $6 \mathrm{~mm}$ & $10 \mathrm{~mm}$ & $14 \mathrm{~mm}$ & $17 \mathrm{~mm}$ \\
\hline 4. & Pseudomonas aeruginosa & $3 \mathrm{~mm}$ & $7 \mathrm{~mm}$ & $11 \mathrm{~mm}$ & $15 \mathrm{~mm}$ & $18 \mathrm{~mm}$ \\
\hline 5. & Klebsiella sp. & $4 \mathrm{~mm}$ & $6 \mathrm{~mm}$ & $10 \mathrm{~mm}$ & $11 \mathrm{~mm}$ & $13 \mathrm{~mm}$ \\
\hline
\end{tabular}

S. aureus: Staphylococcus aureus, E. coli: Escherichia coli, S. typhii: Salmonella typhii, P. aeruginosa: Pseudomonas aeruginosa 
antimicrobial and antioxidant compound. Here in this study, we have isolate marine actinobacterial from a new marine environment which was not reported previously anywhere. Mentioned media for isolation of marine actinobacterial have been widely used in many studies for isolation of marine actinobacterial from different environmental sources. Isolation of a large number of colonies on AIA was reported previously [19]. Similarly, in another study SCA for increased level of

Table 2: Characteristic features of DV-35

\begin{tabular}{ll}
\hline Characteristics & DV-35 \\
\hline Gram staining & Gram-positive \\
Color of aerial mycelium & Off white \\
Melanoid pigment & - \\
Reverse side pigment & + \\
Soluble pigment & - \\
Acid fast staining & - \\
Spore chain morphology & Rectiflexibilis \\
\hline
\end{tabular}

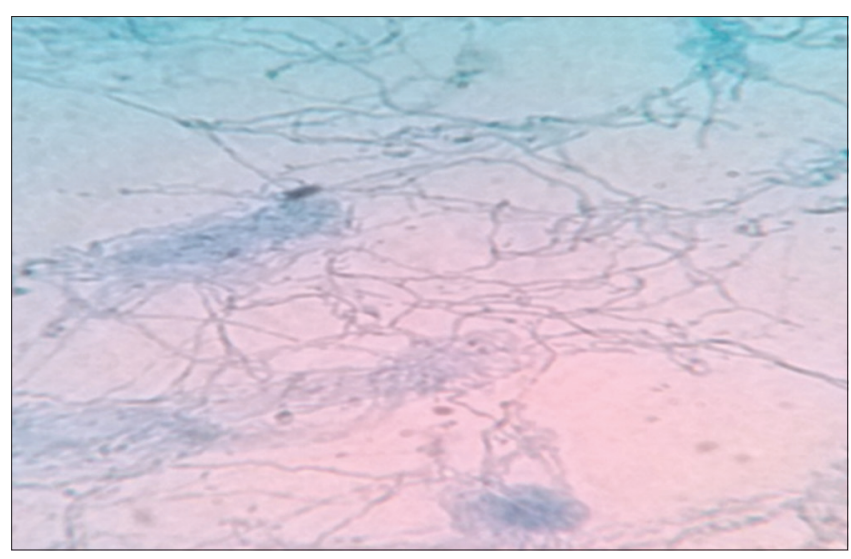

Fig. 3: Spore chain morphology of potential isolates DV-35

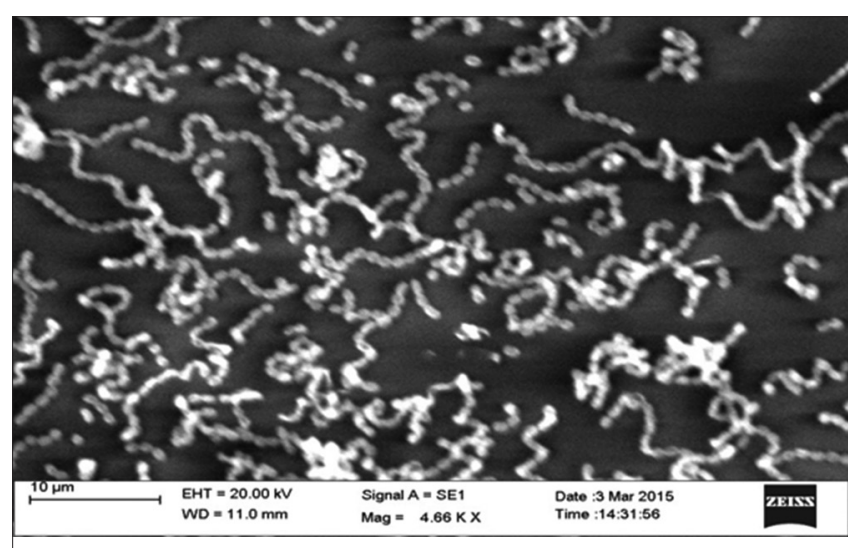

Fig. 4: Scanning electron microscopic image of potential isolates DV-35 marine actinobacterial isolation was reported [20]. In our study, all actinobacterial colonies were isolated on actinobacterial colonies and SCA which is in agreement with the previous reports.

In antimicrobial activity, our extract showed very good activity against both bacterial and fungal pathogens. In a study antibacterial activity of Streptomyces sp. isolated from Sankarabarani River was reported against S. typhi and P. aeruginosa with a zone of inhibition of $17 \mathrm{~mm}$ and $22 \mathrm{~mm}$ respectively [21]. Similarly, in another study marine actinobacteria isolated from Rameshwaram showed antimicrobial activity against P. aeruginosa with a zone of $16 \mathrm{~mm}$ [22]. Our study showed better and similar results when compared with all available reports. Hence actinobacterial crude extracts isolated from Thottada marine sediments can be considered as a potential source for the development of antibacterial drugs. In a previous report, antifungal activity of marine Actinomycetes isolated from Nicobar marine sediments showed low activity against $A$. niger with a zone of inhibition of $10 \mathrm{~mm}$ [12]. Similarly, Streptomyces sp. isolated from marine sediments of Sankarabarani River showed $17 \mathrm{~mm}$ of inhibition against Candida albican [21]. Other reports are available on the antifungal activity of actinobacteria isolated from different sources like Rathnagiri hills, Where Silambarasan et al., 2012 reported antifungal activity $(17 \mathrm{~mm})$ against $A$. flavus [23] Actinobacteria isolated from Pulicat Lake, Tamil Nadu showed very less activity against $A$. niger [24]. Our study has shown better results when compared with all available reports with a zone of inhibition of $18 \mathrm{~mm}$, which makes the finding stronger.

Isolate DV-35 extract also showed a promising hand towards antioxidant drug development. The antioxidant activity of marine actinobacteria isolated from Nicobar marine sediments was reported previously were in DPPH assay extract showed $79 \%$ of activity [14]. Similarly, $85 \%$ of DPPH activity was reported from marine actinobacteria isolated from Chennai marine sediments [15]. When compared with the mentioned results our extract also showed promising data to exploit DV-35 actinobacterial crude extract for the development of antioxidant drugs. In a previous report, marine actinobacteria isolated from Nicobar sediments showed good reducing power assay with an absorbance value of 2.1 at $700 \mathrm{~nm}$ at a dose of $100 \mu \mathrm{g} / \mathrm{ml}$ [14]. In this study, our extract came up with an absorbance value of 1.2 at a dose of $100 \mu \mathrm{g} / \mathrm{ml}$ which also shows the antioxidant potential of actinobacteria crude extract. In a previous report, antioxidant activity of marine actinobacterial isolated from salterns showed $85 \%$ of metal chelating activity [15]. Similarly, in another report, $82 \%$ of activity was reported from Streptomyces sp. isolated from Chennai marine sediments [25]. Our study reported less activity (76\%) when compared with previous results, but $76 \%$ of activity also suggests that actinobacteria isolated from Thottada marine sediments can be considered as a source for the production of the antioxidant agent.

\section{CONCLUSION}

Marine actinomycetes are more miscellaneous and unique with the ability to produce different bioactive compounds. The actinomycetes isolated in the current study may be a part of the entire diversity present in the Thottada marine environment. Here in this study potential isolate showed very good antimicrobial activity against clinical pathogens and also showed excellent antioxidant activity. Our search for the bioactive

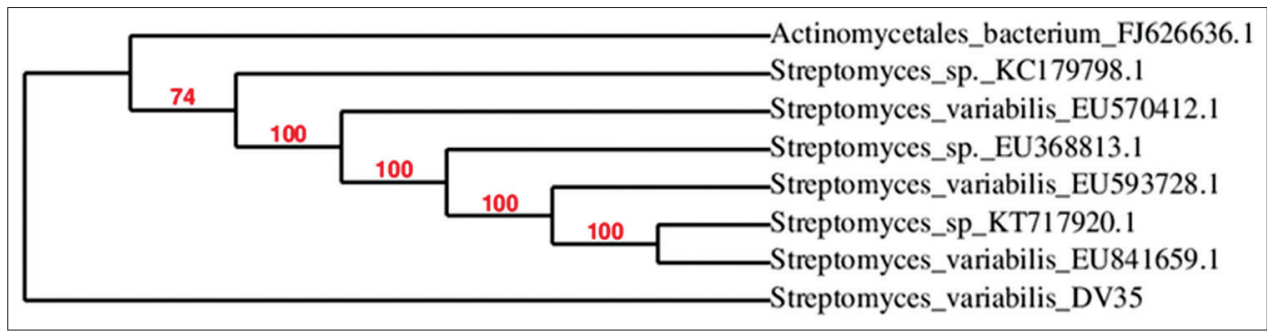

Fig. 5: 16S rRNA sequencing phylogenetic tree view for Streptomyces variabilis DV-35 
potential of actinobacteria has shown that $S$. variabilis DV-35 isolated from Thottada marine sediments, Kannur, Kerala can be used as a promising source for the development of antimicrobial and antioxidant drugs.

\section{ACKNOWLEDGMENTS}

Authors are very thankful to the management of VIT University for providing necessary facilities to carry out this study.

\section{REFERENCES}

1. Jemimah NS, Mohanasrinivasan V, Subathra DC. Novel anticancer compounds from marine actinomycetes: A review. J Phar Res 2011;4(4):1285-7.

2. Saswati R, Choudhury MD, Paul SB. In vitro antibacterial activity of Alocasia decipiens schott. IJPPS 2013;5:155-7.

3. Maragakis LL, Perencevich EN, Cosgrove SE. Clinical and economic burden of antimicrobial resistance. Expert Rev Anti Infect Ther 2008;6(5):751-63.

4. Loomba PS, Taneja J, Mishra B. Methicillin and vancomycin resistant S. aureus in hospitalized patients. J Glob Infect Dis 2010;2(3):275-83.

5. Halaouli S, Asther M, Kruus K, Guo L, Hamdi M, Sigoillot JC, et al. Characterization of a new tyrosinase from Pycnoporus species with high potential for food technological applications. J Appl Microbiol 2005;98(2):332-43

6. Ito N, Hirose M. Antioxidants - carcinogenic and chemopreventive properties. Adv Cancer Res 1989;53:247-302.

7. Gerber M, Astre C, Ségala C, Saintot M, Scali J, Simony-Lafontaine J, et al. Oxidant-antioxidant status alterations in cancer patients: Relationship to tumor progression. J Nutr 1996;126 4 Suppl:1201S-7S

8. Kris Ertherton PK, Harris WS, Appel J. Fish composition, fish oil, fatty acid and their antioxidant activity. Circulation 2012;106:257-74

9. Zhonghui Z. Detection of antitumor and antimicrobial activities in marine organism associated actinomycetes isolated from the Taiwan Strait, China. Chinese J Microbiol Virol 2006;188:87-91.

10. Bull AT, Ward AC, Goodfellow M. Search and discovery strategies for biotechnology: The paradigm shift. Microbiol Mol Biol Rev 2000;64(3):573-606.

11. Okami Y, Hotta K. Search and Discovery of New Antibiotics Actinomycetes in Biotechnology. $3^{\text {rd }}$ ed. New York: McGraw-Hill;
1988. p. 33-67.

12. Karthik L, Gavurav K, Bhaskara Rao KV. Diversity of marine actinomycetes from nicobar marine sediments and its antifungal activity. Pharmacology 2010;1: 221-7.

13. Sunrit BS, Balaram P, Narayan CM. Antimicrobial and Antioxidant activities of two endophytic fungi isolated from Melastoma malabathricum leaves. IJCPR 2016;8:88-92.

14. Karthik L, Kumar G, Bhaskara Rao KV. Antioxidant activity of newly discovered lineage of marine actinobacteria. Asian Pac J Trop Med 2013;6(4):325-32

15. Neethu K, Sathish Kumar SR, Bhaskara Rao KV. Antioxidant and haemolytic activity of tyrosinase producing marine actinobacteria from salterns. Der Pharm Let 2015;7(1):172-178

16. Nonomura H. Key for classification and identification of 458 species of the streptomycetes included in ISP. J Ferment Technol 1974;58:78-92.

17. Shirling EB, Gottlieb D. Methods for characterization of streptomyces species. Int J Syst Bacteriol 1966;16:313-40.

18. Lechevalier MP, Lechevalier H. Chemical composition as a criterion in the classification of aerobic actinomycetes. Int J Syst Bacteriol 1970;20:435-43.

19. Sathish KS, Kokati VB. In vitro antimicrobial activity of marine actinobacteria against multidrug resistance Staphylococcus aureus. Asian Pac J Trop Biomed 2012;2(10):787-92.

20. Baskaran R, Vijayakumar R, Mohanm PM. Enrichment method for the isolation of bioactive actinomycetes from mangrove sediments of andaman Islands, India. Malayshian J Microbiol 2011;7:26-32.

21. Priya M, Anandaraj B, Ganesan T. Antimicrobial activity of estuarine actinobacteria against selected human pathogens. Int J Curr Micro boil App Sci 2015;4:120-5

22. kumar N, Ganesan T, Elavarasi E. Studies on antimicrobial activity of marine actinomycetes isolated from rameswaram. Int J pharm Biol Arch 2013;4:706-10.

23. Silambarasan S, Kumar EP, Murugan T, Saravanan D, Balagurunathan R. Antibacterial and antifungal activities of actinobacteria isolated from rathnagiri hills. JAPS 2012;2:99-103.

24. Radhika R, Amutha K. In vitro antimicrobial activity of marine actinobacteria isolates from Pulicat lake, Tamil Nadu, India. AJPCR 2016;9:184-8.

25. Veena S, Swetha D, Karthik L, Bhaskara Rao KV. Assessment of antityphoid and antioxidant activity of marine Actinobacteria isolated from Chennai marine sediments. Der Pharm Lett 2016;8(3):166-72. 